\title{
The Adolescence-Adulthood Transition and Desistance from Crime: Examining the Underlying Structure of Desistance
}

\author{
Patrick Lussier ${ }^{1}$ Evan McCuish ${ }^{2}$. \\ Raymond R. Corrado ${ }^{2}$
}

Received: 7 November 2014 / Revised: 7 March 2015 / Accepted: 10 April 2015 / Published online: 20 May 2015

(C) Springer International Publishing AG 2015

\begin{abstract}
Describing and explaining desistance in special categories of juvenile offenders, such as chronic, serious, violent, and sexual offenders, represents a challenge for researchers and practitioners alike. In fact, there is little agreement as to how to best define and measure desistance from crime. In the current study, four conceptualizations of desistance are examined with a sample of 349 incarcerated juvenile offenders. Based on longitudinal data measured from age 12 to 23 , desistance was examined through four modeling strategies. Results highlighted inconsistencies in classifying offenders as desisters/persisters across the modeling strategies used. Of importance, following the transition into adulthood, evidence suggests that most of these individuals were not on a life-course pattern of serious, violent, and sexual offending but rather at different stages of desistance. Based on the study findings, a unified model of desistance is proposed to describe and explain desistance from crime among juvenile offenders.
\end{abstract}

Keywords Chronic offending · Desistance $\cdot$ Juvenile offending $\cdot$ Longitudinal data . Recidivism $\cdot$ Sex offending $\cdot$ Trajectory $\cdot$ Violence

From a developmental life-course perspective, the longitudinal view of offending generally includes three key stages, that is, the onset of offending, its developmental course, as well as desistance from crime (e.g., [45]). If desistance from crime, or why individuals stop offending, is the least documented of these three offending stages, there has been a significant increase of theoretical and empirical research conducted on the issue in the past decade or so. Several innovative studies aimed to describe and explain desistance from crime have been conducted. The generalizability of the various

Patrick Lussier

patrick.lussier@svs.ulaval.ca

1 Université Laval, Quebec City, Quebec, Canada

2 Simon Fraser University, Burnaby, British Columbia, Canada 
desistance hypotheses that have utilized longitudinal data from general and at-risk youth drawn from schools, however, has been questioned. While this research, very importantly, has identified factors associated with desistance around the adolescenceadulthood transition, these findings are not necessarily generalizable to certain subgroups of youth involved in serious, chronic, violent, and/or sex offending. Most importantly, the representative samples as well as those based on at-risk youth are not likely to include many chronic juvenile offenders, young murderers, gang members, or juvenile sex offenders. In other words, both theoretically and in policy terms, it is unclear whether the current state of knowledge on desistance is readily generalizable to those youth involved in the most serious forms of crimes or presenting the most serious patterns of offending. More specifically, the current state of knowledge is rather limited regarding these "special categories" of young offenders, therefore, limiting the possibility of drawing specific policy recommendations for the most serious juvenile offenders (e.g., [71]). In that regard, Cernkovich and Giordano [10] confirmed that social bonding mechanisms appear to operate on general samples, but not with institutionalized samples of offenders, which includes more serious offenders. Policy recommendations are also significantly limited by the multiple definitions and operationalizations of desistance used in the scientific literature. In fact, several scholars have stressed the fact that there is limited consensus over the operational definition of desistance (e.g., [42, 57, 83]), with definitions including, among others, the absence of a new arrest in adulthood, the absence of a new arrest in the past 2 years, no (selfreported) offending in the past year, the absence of a new conviction in the past 10 years, and so on (for a review, [39]). The limited consensus over the operational definition of desistance remains a critical issue that will be addressed in the current study. In fact, Kazemian [38] recently stressed the need for developmental life-course researchers to operationalize desistance beyond a single-parameter outcome in order to better capture the changes occurring in the dynamics of offending over time.

While researchers have mainly conceptualized desistance from crime as an event or a process, it is unclear, however, whether the conceptualization of desistance either as an event or a process adequately represents the phenomena among chronic, serious, and violent youth. Every time an offender comes into contact with the criminal justice system, their level of service in terms of risk factors and intervention needs increase. Mulvey et al. [61] very early identified this fundamental limitation when they asserted that previous longitudinal studies have provided little theoretical understanding and policy concerning offenders in the "deep end" of the juvenile criminal justice system. While research on more serious subgroups of juvenile offenders, especially for chronic offenders (e.g., [49]), has dramatically increased in the past two decades with regard to desistance, other subgroups such as violent youth (e.g., $[12,81]$ ) and juvenile sex offenders (e.g., [58, 55, 53, 56]) remain under-researched. Yet, in their study, Sampson and Laub [72] concluded that desistance was the norm even among serious and persistent juvenile offenders. Their study highlighted that previous offending record had little predictive validity regarding lifelong patterns of offending. In other words, the most criminogenic profiles among youth do not guarantee a lifelong pattern of chronic serious and violent offending. These assertions have several important theoretical, empirical, methodological, and policy implications. Therefore, in order to add to this research on desistance from crime, the current study utilized prospective longitudinal data with a sample of largely serious and violent incarcerated young offenders to 
examine desistance during the adolescence-adulthood period by comparing different conceptualizations and measures of desistance. This early adulthood age stage is critical given the long standing age-crime curve perspective that identified a substantial downward trend in prevalence of general offending around this time (e.g., [20]). Recent studies, however, suggest that this downward trend may not characterize all types of juvenile offenders (e.g., [51]). In other words, the age-crime curve is not invariant for all offenders and offense types [43]. The heterogeneity in desistance around the adolescence-adulthood period is the central theme of this study; therefore, it is important first to examine the literature on desistance, particularly, the key conceptualizations of desistance from crime in more detail.

\section{Desistance During the Adolescence-Adulthood Transition}

To date, explanatory models of desistance have focused on the three sets of hypotheses regarding desistance from offending during the adolescence-adulthood period. The first broad set of hypotheses involves two general within-individual change themes that are conducive to desistance from crime. The two leading explanations emphasizing the role and importance of within-individual changes are (a) the maturational hypothesis and (b) the identity change entailing the cognitive transformation of the self hypothesis. The focus is on individual-environment interactions, in particular, the ability to change including openness for change and the environment providing pro-change conditions. The maturational hypothesis is based broadly on adolescents typically becoming more emotionally stable, interpersonally more sophisticated and skilled, and intellectually more knowledgeable and more future-oriented with age. These changes, in turn, increase moral reasoning, reduce impulsivity and facilitate more future-oriented goals and planning. However, this maturation dynamic does not appear to be as prevalent among chronic, serious, and violent offenders as it appears to be in the general population [79]. The second hypothesis has emerged from the study of the narratives of adult offenders and stresses the role and importance of significant, dramatic life events (e.g., a friend being killed during the commission of a crime). Cusson and Pinsonneault [15], for example, conducted interviews with a small sample of former robbers and identified a "shock" resulting from some aversive experience when committing a robbery as playing a key role in the decision to desist. To illustrate, these robbers mentioned the impact of a shoot-out with the police, an accomplice trying to kill them, leaving or committing suicide as examples triggering this shock. These experiences lead these robbers to reassess their participation in crime and reappraise their life goals. Such events may lead to the cognitive transformation of the self or an identity change necessary for desistance to occur, giving them an opportunity to redefine themselves as decent individuals (e.g., [57]).

The second set of hypotheses emphasizes the deterrent role and importance of negative formal and informal consequences of offending on desistance. The underlying process involves successive arrests whereby offenders become more known to the police and criminal justice system officials. This familiarity then results in the increased probability of subsequently not only being arrested but also receiving more punitive legal sanctions. When the negative consequences outweigh the positive and pleasurable aspects of crime, desistance is more likely to occur. The increased punitive probabilities 
supposedly deter offender from future criminal involvement. For example, Cusson and Pinsonneault [15] argued that rather than having an immediate effect, the negative consequences of offending have a delayed deterrent effect for some offenders. They identified four components to this delayed deterrence process. With age and prior crimes cumulating: (a) offenders raise their estimate of the likelihood of punishment; (b) offenders find it more difficult to serve time in prison; (c) offenders experience an increased fear of incurring a long-prison term, and (d) the fear, anxiety, and stress of being caught becomes too overwhelming, spreading into several life domains. In effect, this rational-choice perspective is based on the cumulative impact of formal (e.g., arrest and incarceration) and informal sanctions (e.g., victimization) as well as the negative consequences of the criminal lifestyle (e.g., injuries and fatigue). As a result, the negative consequences of further involvement in crime appear to outweigh the positive or pleasurable aspects of continued offending that moderate the drive to commit a crime. The offender's perception of legal risk has not been shown to be consistently related to the decision to desist from crime (e.g., [74]). Further, in the Cambridge Study in Delinquent Development, Farrington et al. [22] showed that while first convictions have a deviance amplifying effect consistent with a labeling effect, this effect wears off over time whether or not the individual is reconvicted. In fact, research suggests that contact with the criminal justice system may actually lower offenders' perceptions of being caught and convicted for their crime in the future (e.g., [13, 69]).

A third set of hypotheses focuses on the transition to adulthood and access to adult roles that diminish the acceptability and efficacy of delinquent behaviors. Marriage, parenthood, and employment are key examples of essential turning points that typically constitute powerful informal social controls that can impact routine activities, criminal opportunities, and reduce offenders decisions to continue offending into adulthood (e.g., [43, 73]). From this perspective, it is not solely the presence of these life events and turning points, but their quality and stability involving strong prosocial ties in different contexts (e.g., at home and at work) with prosocial peers that disapprove of deviant behaviors while promoting prosocial ones that influence desistance (e.g., [40]). In other words, most adult routine roles are inconsistent with a delinquent lifestyle, which usually is characterized by unstructured and unsupervised routines activities. The adult roles, in contrast, involve structured and prosocial expectations that work, intimate relationships, family, and community roles may bring. Once these new adult roles are established, they become valued and are, therefore, protected and guarded [61]. As with the above hypotheses, there is research that challenges any simple correspondence between the young adulthood stage and the access to prosocial turning points. Unlike life-course criminologists, developmental criminologists assert that turning points and life transitions in the initial adulthood stage are more problematic and are even relatively dependent on an individual's developmental history (e.g., [51]). In other words, theorists questioned whether most, let alone all, older adolescents and young adults either have sufficient access to prosocial adult roles or can benefit from their influence to desist from crime. Regarding the latter theme, there is research that indicated that these early stages' entry into work and marriage were not associated with a decrease in offending and, even possibly, contributed to the maintaining of offending $[19,63]$. For example, according to Uggen [82], only after about age 26 did work appear to become a turning point with respect to desistance. Furthermore, longitudinal research examining long-term criminal careers show that such age-graded changes in 
life circumstances only have a modest impact on offending [5]. Despite this difference concerning the age stage when turning points typically have the most pervasive effect on desistance, these theoretical perspectives are not necessarily contradictory. Yet, there have been only limited attempts to integrate them into a unified model of desistance in part because of continuing debate concerning the conceptualization of desistance.

\section{The Conceptualization of Desistance from Crime}

Despite the intuitively obvious conceptualization of desistance (i.e., not recidivating), this construct has engendered serious conceptual difficulties that has limited theoretical and policy development. In fact, there is a lack of agreement as to what constitutes persistence and desistance from crime (e.g., [65]). The importance of being clear about what desistance is was shown in a study by Bushway et al. [9] which highlighted that the operationalization of desistance as an event or as a process identified different individuals as desisters (see also [77]). This conceptual issue also raises the question of whether desistance consists of a single event or involves multiple phenomena? In addition, there is the issue of whether desistance is qualitatively or quantitatively a different phenomenon across offenders? While criminologists have typically focused on distinguishing desistance as a process or as an event, the scientific literature in the field of correctional psychology, until recently, has depicted desistance somewhat differently than an event or a process, presenting desistance in probabilistic terms. Others, such as developmentalists, have discussed desistance as a rather predictable phenomenon relatively bounded to a specific offending pattern. The presence of different, yet limited number of offending patterns, suggests that there are distinct pathways out of crime. Taken together, researchers have approached the issue of desistance in four ways: desistance as an event, in probabilistic terms, as a process, and bounded to specific offending trajectories. These four conceptualizations of desistance are presented below.

Desistance As An Event Based on criminal career research, desistance is conceptualized as an event involving the abrupt termination of offending. From this standpoint, therefore, desistance is sudden. Yet, it has not been evident that all or even most offenders terminate offending immediately following their last offense or much later. In that context, desistance from offending is operationalized as a non-offending state and the maintenance of this state for a certain time period. Hence, recidivism, or an offending state (i.e., committing crimes), is considered to be the opposite of desistance (i.e., persistence). Researchers usually consider a broad definition of recidivism (e.g., have committed a new offense, a new arrest, or conviction) to be able to show that termination is not just the result of crime switching. Researchers, however, somewhat disagree as to how long a significant non-offending state needs to be to be indicative of desistance (i.e., 1 year, 3 years, and 5 years; e.g., [74]). The intermittency of offending for some offenders $[73,67]$, therefore, may lead to issues of false negatives or the false identification of someone as a desister, when in fact, with a longer follow-up period, these individuals do reoffend [9]. Methodologically, desistance from crime as an event is the least sophisticated operationalization. The simplicity of the operationalization of desistance is counterbalanced by significant issues related to the subjective nature of the 
length of the non-offending state. Of course, the solution is to follow individuals until death, but this is seldom feasible (Mulvey et al. 2004). Still, Kazemian [37] argued that desistance from crime unlikely occurs abruptly and that the sole emphasis on termination of offending may overlook important and valuable information on the criminal careers of offenders, particularly chronic offenders.

Desistance in Probabilistic Terms Unlike the event perspective, the probabilistic conceptualization of desistance stresses that offenders remain at risk of recidivism over a long-time period. Not surprisingly, this approach has been associated primarily with correctional psychology and, in terms of policy analysis of desistance, it has been one, if not the most influential perspective. Samples of adult inmates having committed more serious offenses (e.g., assault, sexual assault, and drug-related offenses) or with a lengthy criminal history such as multi-recidivists and chronic offenders have been the focus of this research. As part of the probability perspective, known offenders are always assumed to be at some risk of offending, but differ in terms of their likelihood to reoffend over time. The risk of recidivism is usually expressed in probabilistic terms (i.e., low risk, moderate risk, and high risk). Conversely, desistance is expressed in probabilistic terms by considering the risk level of recidivism. This probabilistic perspective is theoretically relevant in the context of the adolescenceadulthood transition in samples of chronic, violent, and sex offenders because recidivism studies have consistently shown that young adults have higher recidivism rates (e.g., [25]). The length of the follow-up period is critical to the identification of recidivists because offenders remain at-risk of offending in the long-term and time-at-risk for reoffending has been incorporated in several validated instruments used in corrections and parole services to provide probability based risk estimates of recidivism. Historically, increasingly sophisticated statistical techniques have been employed to compute such probabilities. Therefore, to avoid issues of right censoring of the data, survival models have been utilized to model risk (e.g., Cox proportional hazards) or model how long an offender survives in the community without committing a new crime. The strength of the survival model is that it adjusts for time at-risk of offending following any specific starting time point (e.g., prison release).

Desistance As A Process Whereas the above conceptualizations of desistance consider it as either an abrupt termination or a probabilistic phenomena, developmental criminologists emphasize desistance as a time-based process toward termination of offending (e.g., [45, 50]). In other words, this third perspective is concerned with understanding the transition from offending to non-offending, rather than non-offending itself. Bushway et al. [8], for example, defined desistance as the process of reduction in the rate of offending from a non-zero level to a stable rate empirically indistinguishable from zero. While this specific formulation involves a mathematical definition of desistance, the theoretical focus is the understanding and specification of risk and protective factors that affect the transition from offending to non-offending. For example, building human and social capital is not immediate; it takes time, and consequently, offending may, as a result, be characterized by intermittent periods of 
offending (e.g., [43]). In effect, desistance is described as a process that involves stages where gradual but not necessarily automatic or consistent reduction of offending occurs prior to complete termination. Reoffending lapses, therefore, are expected, but at a gradually and eventually lower rate until termination. When traditional measures of recidivism (e.g., having been arrested for a new offense) are used, persistent offenders and offenders in the process of desisting can be confounded into a single category: the recidivist. Conversely, intermittent offenders (i.e., active offenders), offenders in the process of desistance, and offenders having completely desisted can be confounded into another misleading category: the non-recidivists. In other words, individuals in a desistance phase may still be involved in crime and continue to have contact with the justice system. In the context of the adolescence-adulthood transition, it is expected that as the young offender ages, their offending may go through a deceleration process until termination. In fact, research has shown that lambda (i.e., the rate of offending) tends to decrease with age [67]. Desistance as a process requires multiple assessments of offending to capture the de-escalation or gradual decline in offending. Research has investigated deceleration in offending using dynamic classification tables (e.g., [3, 47]). Such tables are useful to present the proportion of offenders decelerating, as well as those whose offending is relatively stable or accelerating. The problem with the dynamic classification table is that it does not control for or take into consideration time at risk and periods during which offenders were not in a position to reoffend (e.g., incarcerated).

Offending Trajectories and Desistance According to the fourth perspective, desistance is considered as part of specific offending trajectories. Offending trajectories consist of patterns delineating onset, course, and termination of offending over time. This perspective asserts that there are relatively few, but stable and predictable, longitudinal patterns of offending (e.g., [6]). Further, desistance is hypothesized to be intrinsically linked to both the age of onset of offending and the course of offending. There is a consensus that the age of onset of offending is statistically related to longer criminal careers [21]. It is suggested, therefore, that desistance is relatively predictable from specific patterns of onset of offending that can be used to predict desistance. Researchers have formulated hypotheses regarding desistance from crime based on the age of onset of offending distinguishing early and late starters, with an emphasis on the adolescence-adulthood transition (e.g., [60, 64]). Researchers have theorized that lateonset, also known as adolescence-onset offending, is more likely to be associated with a pattern of desistance prior to or immediately during the initial adult transition period than early, childhood-onset of offending. The explanation rests on the developmental perspective assertion that late entry into delinquency more typically involves youth who have benefited from prosocial influences and learned the necessary prosocial skills to adjust to the adolescence-adulthood transition prior to their delinquency involvement (e.g., [60]). To measure and identify such patterns, techniques such as groupbased modeling or latent-growth curve modeling have been utilized by researchers to identify trajectories and patterns of desistance from crime (e.g., [62]). Very importantly, longitudinal studies conducted employing at-risk samples have shown that the adolescent-limited pattern of offending with desistance prior to age eighteen is a 
relatively rare phenomenon. For example, the Bushway et al. [9] study found that a trajectory described as "bell-shape desistors," an offending pattern that resembled the classic age-crime curve, comprised only $8.5 \%$ of the sample of at-risk youth. More specifically, for most youth included in this sample, desistance from offending occurred after age 18. Yet, the adolescent-limited desistance type has questionable explanatory relevance regarding desistance patterns of more serious patterns of offending, such as chronic, violent, and sex offenders. The current study aims to examine the relevance of offending trajectories, including the adolescence-limited pattern with a sample of institutionalized youth.

\section{Study Aims}

Most research on patterns of desistance from crime during the adolescence-adulthood transition has been based on large surveys of community samples, and therefore, understandably, usually had low subsamples of adjudicated youth and most importantly, incarcerated youth involved in chronic, serious, violent, and/or sex offending. The current study examines the patterns of desistance during the adolescence-adulthood period using four different conceptual frameworks that are rarely examined simultaneously, especially with large samples of chronic, serious, and violent offenders. In fact, prior studies have rarely compared and contrasted multiple conceptualizations of desistance from crime. One study that did so showed that different operationalization of desistance identified different individuals as desisters (e.g., [9]). To our knowledge, no study has compared the four identified conceptualizations, that is, desistance as an event, a process, in probabilistic terms and as part of an offending trajectory. The current study, therefore, extend the work of Bushway et al. [9] by comparing distinctive ways of approaching and measuring desistance from crime in a single study. This replication is significant in another way given that the Bushway et al. [9] study did not include one of the most commonly referred conceptualization of desistance used in the juvenile/adult justice system, that is, desistance in probabilistic terms. Further, research on desistance has been focused on community-based samples of youth and too rarely on youth in the deep end of the juvenile justice system [61]. Given that findings from communitybased samples may not be generalizable to this subgroup of youth (e.g., $[10,11])$, the current study focuses on incarcerated youth perceived by the juvenile justice system to be on a life-course persistent offending trajectory. The primary purposes, therefore, are to assess whether subgroups of these young offenders differ in their desistance patterns and whether the four frameworks can be utilized to describe these patterns. In other words, is it possible that desistance as an event applies more to specific subgroup of juvenile offenders, whereas the de-escalation process applies more to another subgroup of juvenile offenders? Currently, the theoretical approach informing the research on desistance implies a one-size-fits-all hypothesis. The current prospective longitudinal study aims to clarify this by examining the four key approaches to desistance in chronic offenders, serious and violent offenders, as well as juvenile sex offenders. The study focuses on the adolescenceadulthood transition as it marks a pivotal transition point likely to bring changes in the social environment of these individuals. 


\section{Methodology}

\section{Sample}

Data for the current study were derived from the Incarcerated Serious and Violent Young Offender study conducted in British Columbia, Canada, which has been ongoing since 1998. As part of this study, adolescent offenders between the ages of twelve and nineteen were interviewed in open and secure custody facilities within the Greater Vancouver Regional District and surrounding areas. To restrict the use of custody for adolescents under the Youth Criminal Justice Act, judges must only consider incarceration as an option if the offender was deemed to have committed a serious or violent offense (see [4]). Therefore, a commonality between all youth included in the sample, was that they were considered by the courts to be serious and/or violent young offenders. Therefore, this sample of Canadian incarcerated adolescent offenders $(n=$ 349 ) is very specific, and the generalization of the presented findings should be done with caution. All individuals included in the sample were in youth detention at least once during adolescence. It excludes youth who were convicted but received a noncustodial sentence. The sampling strategy used here makes sense in the context of the current focus on youth involved in more serious offending patterns. To be included in this follow-up period, individuals had to have completed an interview at least 7 years prior to December of 2013. Details about the sample characteristics are presented in Table 1 . The sample is overwhelmingly composed of male $(81 \%)$ and Caucasian ( $57 \%$ ) offenders. There is, however, a well-known overrepresentation of Aboriginals in detention, and the current study is no exception. Specifically, the percentage of Aboriginal offenders in the current study $(27.3 \%)$ was substantively higher than within the general population of British Columbia (6.2\%; Statistics Canada 2013). Additionally, because this was a Canadian-based sample, the percentage of Aboriginal offenders was dissimilar from incarcerated adolescent offenders in the USA (e.g., Teplin et al. [78], though the over-representation of Aboriginal offenders in Canada is similar to the over-representation of African American and Hispanic offenders in the United States. ${ }^{1}$ The sample is by no means representative of all youth involved in crime in the province of British Columbia. It is representative, however, of offenders in the Canadian youth justice system sentenced to detention youth with more serious patterns of offending or those having committed serious offenses. Indeed, youth included in the sample have been sentenced, on average, 6.4 times between age 12 and 17. On average, they have been sentenced 3.9 times in adulthood, which already suggests a decline in official offending across the two time periods.

\section{Procedures}

The purpose of the Incarcerated Serious and Violent Young Offender study was to conduct interviews with juvenile offenders and collect file-based information on risk factors associated with the onset, persistence, and desistance of adolescent criminal

\footnotetext{
${ }^{1}$ The over-representation of Aboriginal offenders in custody is also present in states such as Alaska, North Dakota, South Dakota, and Montana, where Native Americans account for 29-42\% of all youth in custody (Cross 2008).
} 
Table 1 Descriptive information about the sample

\begin{tabular}{lll}
\hline Individual characteristics & Percentage & Mean (SD) \\
\hline Gender & & \\
Male & 81.1 & \\
Female & 18.9 & \\
Ethnic origin & & \\
Caucasian & 57.0 & $14.1(1.4)$ \\
Aboriginal & 27.3 & $10.2(7.0)$ \\
Asian & 7.8 & $6.4(4.4)$ \\
Other & 7.9 & $3.9(4.2)$ \\
Age at first court appearance & & \\
Number of sentencing dates & & \\
Total & & \\
Age 12 to 17 & & \\
Age 18 to 23 & & \\
Juvenile offending & & \\
Non-recidivists & 13.2 & \\
Recidivists & 43.8 & \\
Chronic & 43.0 & \\
Serious offending & & \\
Adolescence & 74.2 & \\
Adulthood & 55.0 & \\
Violent offending & 65.3 & \\
Adolescence & & \\
Adulthood & & \\
Sex offending & & \\
Adolescence & & \\
Adulthood & & \\
\hline & & \\
& & \\
\end{tabular}

activity and to identify risk factor profiles associated with the development of serious and violent offending. To recruit research participants, informed consent was first sought from and provided by the British Columbia Ministry of Child and Family Development (MCFD). MCFD serves as the legal guardian to all youth in custody, and their consent allowed the research team to approach all youth in custody centers throughout the province of British Columbia. Youth were approached by a member of the research team at their respective custody center and asked whether or not they wanted to participate. All subjects were read and given a copy of an information sheet which explained the purpose of the study, how information would be collected (e.g., interview and file information), and that all information would be kept confidential by law unless the subject made a direct threat against themselves or someone else. Youth who agreed to participate in the study were asked to sign a consent form signifying that they had been read and understood the details of the study that had been provided in the information sheet. They were also informed that the data collected was for research 
purposes only and the decision to participate (or not) in the study would have no positive or negative consequences on their stay. Only approximately $5 \%$ of youth declined to participate. For those youth who agreed to participate, research assistants were granted access to case management files, which contained subjects' presentence reports, criminal record, and information on their behavior while in the institution. Some subjects lied about their age, the offense they were incarcerated for, or underreported the numbers of offenses they committed. Access to file information and official records, therefore, was essential for this study.

\section{Measures}

Official Offending Prior studies have often relied on self-report information to assess desistance from offending, which may be relevant in the context of measuring nonserious offenses that are more common and less likely to be detected. Certainly, the criticisms of official records are warranted and justified. While the utility of self-report studies is undeniable (e.g., [32]), they are not without limitations either (e.g., [11, 28]). For example, a substantial body of literature from the field of forensic psychology/risk assessment notes that impression management/social desirability is common among offenders, especially those in the "deep end" of the justice system. Some offenders will over-report delinquency, especially non-violent offenses, to appear "hardened" (e.g., see [35]). More experienced offenders will under-report their offenses, especially serious and violent offenses for fear of reprisal. Furthermore, Gilman et al. [26] recently showed that the prevalence of the continuity of offending was actually higher for official data compared to self-report data. Farrington et al. [23] reported that the age of desistance was generally later according to convictions. This may be due to concealment at an older age, but still speaks to the limitations of self-report data in measuring desistance. Dubow et al. [17] demonstrated moderate to high concordance between official and self-report measures. This concordance varies, however, across crime types. Fontaine et al. [24] demonstrated that it is rare for a chronic offender (based on self-report data) to not have official convictions. Further, they showed concordance between self-report violent offending and official violent offending during adolescence. This concordance was significantly stronger for violent and non-violent offending. Of course we are never going to capture desistance perfectly using official data, but it is wrong to suggest that using official data is not a valid method of studying desistance. While official data has the disadvantage of underestimating offending, the current study focuses on official data given that focus is on more serious crimes that are unlikely to be reported in self-reports (e.g., rape, homicide, and assault; e.g., see [77]) and to minimize recall bias issues.

Offending was measured using official data using British Columbia Corrections' computerized system, Corrections Network (CORNET), which contains information pertaining to each offender's movement in and out of custody as well as the exact criminal offense, date of conviction, and sentence type. Using data from this computerized system, criminal convictions were coded for the entire sample from age 12 up to age 23. The start of the follow-up period, age 12, was used considering that it marks the minimum age of criminal responsibility in Canada. From that point on, every criminal charge that resulted in a conviction was coded. For this sample, the average number of charges for which the individual was convicted for was $19.3(\mathrm{SD}=14.3)$. The median 
number of convictions was 17 , showing that the high number of convictions found on average was not an artifact of a small subgroup of individuals. Although it was possible for offenders to commit new offenses while outside of the province, the current study had access only to records of offenses committed within the province of British Columbia. During the follow-up period, six offenders died and three moved outside the province. None were deceased or moved outside the province prior to turning 18 years old.

Age of Onset Age of onset has been shown to be related to frequency, persistence, and seriousness of offending in past studies (for a review, Le Blanc and Loeber [46]). In line with prior empirical investigations, the age of onset was operationalized in the current study as the offender's age at the time of their first court appearance for a crime. For this sample, age at first court appearance was, on average, 14 years old. In total, 12.9 and $25.3 \%$ first appeared in court at 12 and 13 years old, respectively.

Chronic Offending Chronic offending is a term often used by criminologists to refer to a stable and sustained pattern of offending during some time period. Chronic offending is usually operationalized by using a cutoff number of arrests/convictions. Prior studies have criticized that such practice is arbitrary, and alternative methods have been proposed. One method is to examine recidivism probabilities across each arrest/ conviction and determine the point where recidivism probabilities become high and stable (e.g., [68]). This method was selected for the current study. The recidivism probabilities for each $X_{t+1}$ conviction, where $t$ is the first conviction, were plotted on a graph. A break in recidivism probabilities was observed at the seventh sentencing date during adolescence. The same pattern was observed in adulthood. Using this finding, it was decided to categorize offenders as follows: (a) non-recidivists, i.e., those with only one sentencing date; (b) recidivists, i.e., those with at least two and less than seven sentencing dates; and (c) chronic offenders, i.e., at least seven sentencing dates. This operationalization was applied to juvenile offending and adult offending separately. In total, $43 \%$ of the sample were chronic juvenile offenders and $24.6 \%$ were adult chronic offenders (Table 1). This operationalization of chronic offending is quite similar to those used in previous investigations (e.g., at least five arrests; see [49]).

Serious, Violent, and Sex Offending In keeping with prior investigations (e.g., [49]), serious offending refers to violent crimes, drug-related offenses, and weapon-related offenses. Serious offending was included to capture, at least in part, youth involved in gang-related activities, an issue in the province of British Columbia, Canada [16]. Close to three-quarters of the sample $(74.2 \%)$ had at least one charge for a serious offense during adolescence while a little over half $(55 \%)$ did in adulthood. Violent offending referred to legal definitions of violence and includes offenses such as homicide, assault, serious assault, assault with a weapon, and threats. In total, $65.3 \%$ of the sample had at least one charge for a violent offense during adolescence, but the prevalence of official violence dropped to $43.3 \%$ in adulthood. Moreover, sex offending referred to such offenses as sexual assault, sexual assault with a weapon, sexual assault causing bodily harm, sex offenses against a minor (e.g., sexual interference and sexual contact with a minor), and other sexual offenses (e.g., incest and voyeurism). This definition of sex offending did not include offenses related to 
prostitution. In total, $16 \%$ of the sample had at least one charge for a sex crime during adolescence, but only $5.4 \%$ did in adulthood. In all, the prevalence of serious, violent, and sex offending dropped from adolescence to adulthood.

Exposure Time Exposure refers to the time period the individual was at-risk of offending. In other words, the current study controls for the amount of time that offenders would be unable to commit any offenses due to the lack of opportunity created by detention. Using information uploaded to the CORNET system, each date of admission and date of release from custody was recorded for each offender. A measure of exposure time should be especially critical for all studies using an offender or at-risk sample given the substantial amount of time spent in custody. Total time spent in custody was also calculated and controlled for. On average, offenders spent 357.8 $(\mathrm{SD}=294.2)$ days in custody during adolescence and $434.6(\mathrm{SD}=533.3)$ days in custody during adulthood.

\section{Results}

\section{Specific Indicators of Desistance}

Non-Offending State in Adulthood In total, based on official data on offending, $24.4 \%$ of the full sample maintained a non-offending state in adulthood. Three covariates were entered into a logit regression model (not shown), that is, gender, ethnic origin, and age at the first court appearance to predict desistance from offending. The model was statistically significant $[-2 \mathrm{LL}=360.3, d f=4, p<.01]$. Among the tested covariates, only gender was statistically associated with the maintenance of a nonoffending state in adulthood. Females were 3.04 times $(p<.001)$ more likely than males to maintain a non-offending state in adulthood.

Offending Trajectories and Desistance Semi-parametric group-based modeling (SPGM) was used to analyze the annual number of convictions for each offender included in the sample between age 12 and 23 [62]. Unlike cluster analysis and other grouping methods, SPGM does not identify groups ex ante but instead allows distinct trajectory groups to emerge from the data. To control for time at risk, exposure time was built into the SPGM model by adapting Piquero et al.'s [66] original formula. This adaptation adjusted for high standard errors and improbable rates of offending by constraining the minimum exposure time ${ }^{2}$ to be approximately 0.2 :

$$
\text { Exposure }_{j i}=1-(\text { Number of Days Incarcerated } / 455)
$$

where $j$ is the respondent and $i$ is the year of observation.

The SPGM analyses in the current study proceeded in two stages, the first involved model identification, which focused on identifying the number and shape of the

\footnotetext{
$\overline{2}$ The minimum exposure time ( 0.20$)$ equates to spending approximately 2 months in the community if the offender was incarcerated for one year.
} 
offending trajectories that best fit the data. Trajectory analyses were conducted in SAS 9.3 using the Proc TRAJ add-on developed by [34]; see also [33]). The zero-inflated Poisson (ZIP) model with quadratic functional form was used to estimate the distribution of the offending trajectories. Bayesian Information Criteria (BIC) values were used to identify the number of offending trajectories that best represented the data. A fourgroup quadratic model resulted in a BIC value of $-7,127.21$, which was closer to zero than both a three-group model and a five-group model (see Appendix A). BIC values for a four-group solution with quadratic functional form were also closer to zero than the same model with cubic functional form. ${ }^{3}$ Based on the BIC values of a ZIP model with quadratic functional form (see Appendix A), there was strong evidence for a four group model over a five group model $\left(B_{i j}>10\right)$ but not for a three group model over a four group model $\left(\mathrm{B}_{\mathrm{ij}}<10\right)$. The parameters of the four-group model are outlined in Table 2 and help support the retention of a four group model. Classification accuracy based on the average posterior probability of accurately assigning individuals to a particular trajectory was high for all four trajectories (range of 0.88-0.94). Finally, the odds of correct classification (OCC) were used to help provide confidence that individuals were assigned to the appropriate trajectory group. OCC values for each trajectory group were calculated as:

$$
\mathrm{OCC}_{\mathrm{g}}=\left(\operatorname{AvePP}_{\mathrm{g}} /\left(1-\mathrm{AvePP}_{\mathrm{g}}\right)\right) /\left(\prod_{\mathrm{g}} /\left(1-\prod_{\mathrm{g}}\right)\right)
$$

where $\prod_{g}$ is the estimated size of group $g$ (see [75]).

As indicated in Table 2, OCC values ranged from 7 to 15, higher than Nagin's [62] conclusion that $\mathrm{OCC}$ values of at least five were indicative of high classification accuracy.

A graphical representation of the four group solution is presented in Fig. 1 and was used to aid with the second stage of analysis: model interpretation. The four identified offending trajectories were as follow. First, a group of low rate offenders was identified. They represented $20.6 \%$ of the sample. These individuals average less than one conviction annually throughout the follow-up period (age 12 to 23), with their offending frequency somewhat peaking at age 16-17. After age 18, this pattern shows that official offending is relatively non-existent. The second group, the slow riser chronic, represents $23.5 \%$ of the sample. Offending gradually accelerated from age 12 on, peaking at age 16, after which offending remained relatively stable averaging between three and four convictions. The third offending trajectory, the high rate chronic, represents $14.0 \%$ of the sample. This pattern showed a rapid increase in offending frequency, starting at age 12 , peaking at age 17 , at this point averaging about five convictions annually. From age 18 to 23, this pattern shows a downward trend with evidence of some deceleration. At age 23, they remained, with the slow riser chronic, the most active group. Finally, the bell-shaped pattern is the most prevalent group, representing about $41.8 \%$ of the sample of young offenders. This group mirrors an adolescent-limited offending pattern. The bell-shaped pattern shows a gradual increase of offending from age 12 on, peaking at age 15, averaging about three convictions

\footnotetext{
${ }^{3}$ In addition, Jeffreys' scale of evidence based on the Bayes factor approximation was used to determine whether there were substantive differences in BIC values between models specifying a different number of trajectory groups (e.g., [62]). Jeffrey's scale of the evidence of the Bayes factor is calculated as Bayes factor calculated as $e^{\mathrm{BICi}-\mathrm{BICj}}$ where values of $\mathrm{B}_{\mathrm{ij}}$ greater than ten indicate strong evidence for model " $i$ " (see [62]).
} 
Table 2 A semi-parametric analysis of offending trajectories among the sample of adjudicated youth

\begin{tabular}{lllll}
\hline & Offending trajectories & & \\
\cline { 2 - 4 } & Low rate & Bell-shaped & High rate chronic & Slow riser chronic \\
\hline$n(\%)$ & $72(20.6)$ & $146(41.8)$ & $49(14.0)$ & $82(23.5)$ \\
Estimated model parameters & & & & \\
Intercept & -17.39 & -5.50 & -1.29 & -6.15 \\
Linear & 2.38 & 0.96 & 0.47 & 0.82 \\
Quadratic & -0.08 & -0.03 & -0.02 & -0.02 \\
Model fit characteristics & & & & 16 \\
Peak age & 16 & 15 & 17 & 0.98 \\
Median group probabilities & 0.95 & 0.98 & 1.00 & $0.41-1.00$ \\
Range & $0.50-1.00$ & $0.51-1.00$ & $0.59-1.00$ & $0.00(0.00)$ \\
Mean probability-low rate & $0.88(0.15)$ & $0.12(0.14)$ & $0.00(0.00)$ & $0.02(0.07)$ \\
Mean probability-bell-shaped & $0.06(0.12)$ & $0.91(0.14)$ & $0.01(0.06)$ & $0.05(0.10)$ \\
Mean probability-HLC & $0.00(0.00)$ & $0.01(0.04)$ & $0.94(0.10)$ & $0.92(0.13)$ \\
Mean probability—SRC & $0.00(0.00)$ & $0.04(0.09)$ & $0.04(0.09)$ & 11.39 \\
OCC & 7.26 & 10.01 & 15.36 & \\
\hline
\end{tabular}

Note: $H L C$ high-level chronic, $S R C$ slow riser chronic, $O C C$ odds of correct classification

annually. After this point, offending decelerated, mirroring the low-rate group in adulthood in terms of offending rate.

Next, a multinominal regression analysis (not shown) was performed to examine the covariates (gender, ethnic origin, and age at first court appearance) of offending trajectories. Considering that only the slow-rising chronic did not show some form of desistance (i.e., near zero offending in adulthood or a slowing down of offending frequency), this group was used as a reference category to whom the other three groups were compared to. The regression model was statistically significant $[-2 L L=219.90$, $d f=12, p<.001]$. For the high-rate chronic group, only age at first court appearance was

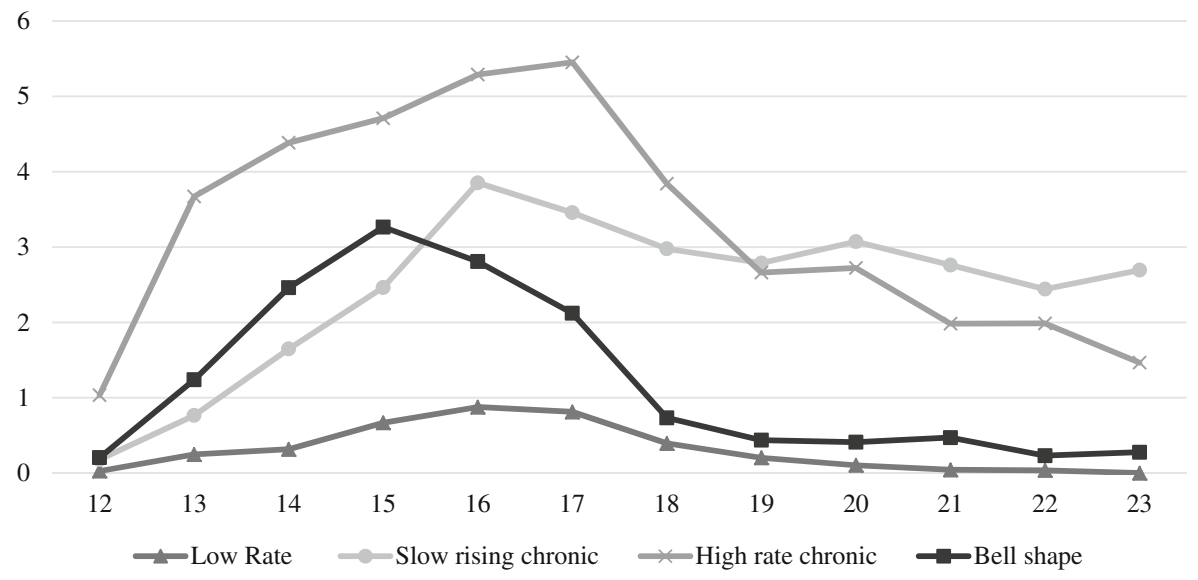

Fig. 1 Offending trajectories of adjudicated youth from 12 to 23 years old 
a significant covariate. High-rate chronic offenders tend to have their first court appearance earlier than the slow-rising chronic $(\mathrm{OR}=.74, p<.05)$. Furthermore, females were 9.2 times more likely to be following the bell-shaped trajectory group than the slow-rising chronic group $(p<.001)$. There were no other statistically significant covariates associated with the bell-shape trajectory. For the low-rate group, all covariates were statistically significant. Indeed, the low-rate group, as opposed to the slowrising chronic, were more likely to include females $(\mathrm{OR}=5.7, p<.01)$, to have a first court appearance later in adolescence $(\mathrm{OR}=1.9, p<.001)$, but were less likely to be Aboriginal $(\mathrm{OR}=.30, p<.05)$ or Caucasian $(\mathrm{OR}=.26, p<.05)$. It is implied, therefore, that the slow riser chronic group were more likely to be composed of Asians, Blacks, and youth from other ethnic minorities.

Desistance As A Deceleration Process In Table 3, desistance is presented as a deceleration process. Using a dynamic classification table (e.g., Ayres et al. [3]), offending status based on the number of sentencing dates during adolescence (i.e., non-recidivists, recidivists, and chronic) was cross-tabulated with the offending status in adulthood (i.e., abstainers, non-recidivists, recidivists, and chronic). The analysis reveals a significant statistical association between the two periods in terms of offending status $\left[\chi^{2}(6)=54.1, p<.001\right]$. In other words, offending status in adulthood was not random and statistically related to offending status in adolescence. However, a closer inspection of the data highlight that the majority of the sample of young offenders showed a pattern of desistance from adolescence to adulthood. In total, $54.2 \%(n=189)$ of the sample showed some form of deceleration from adolescence to adulthood, while $34.1 \%$ (119) showed relative stability in offending and only $11.7 \%$ showed a pattern of acceleration over the two observational periods. Note that chronic juvenile offenders could not technically accelerate in adulthood due to a ceiling effect. When excluding this group, $20.6 \%$ of this sample accelerated in adulthood. Of importance, deceleration was not limited to a specific group of young offenders but

Table 3 Decelerating and accelerating patterns of offending from adolescence to adulthood in adjudicated youth

\begin{tabular}{|r|c|c|c|c|}
\hline & \multicolumn{4}{|c|}{ Adult offending status (18-23) } \\
\hline $\begin{array}{l}\text { Juvenile offending status } \\
(12-17 \text { y.o. })\end{array}$ & Abstainers & Non-recidivists & Recidivists & Chronic offending \\
\hline Non-recidivists & 20 & 16 & 8 & 2 \\
& $(43.5 \% / 5.7 \%)$ & $(34.8 \% / 4.6 \%)$ & $(17.4 \% / 2.3 \%)$ & $(4.3 \% / 0.6 \%)$ \\
Recidivists & 45 & 27 & 50 & 31 \\
& $(29.4 \% / 12.9 \%)$ & $(17.6 \% / 7.7 \%)$ & $(32.7 \% / 14.3 \%)$ & $(20.3 \% / 8.9 \%)$ \\
Chronic offending & 20 & 13 & 64 & $(35.3 \% / 15.2 \%)$ \\
\hline
\end{tabular}

Note: $n=349$. The number of individuals are presented in cells with associated percentages. The first percentage reflects the row percentage ( $\%$ of non-recidivists who are abstainers in adulthood), while the second percentage reflects what is based on the full sample $(\%$ of the sample who were chronic offenders in both time periods)

Light gray area $=$ deceleration, white area $=$ stable, dark gray area $=$ acceleration 
was observed among non-recidivists, recidivists, and chronic offenders. Indeed, $43.5 \%$ of juvenile non-recidivists, $47 \%$ of juvenile recidivists, and $64.7 \%$ of juvenile chronic offenders decelerated from adolescence to adulthood.

Next, a logit regression model was examined to identify possible covariates of deceleration. To do so, accelerators and individuals whose offending was stable were combined and compared to the decelerators. The regression model was statistically significant $[-2 \mathrm{LL}=429.5, d f=4, p<.001]$. Of the three covariates examined, gender and age at first court appearance emerged as significantly associated with deceleration. Individuals more likely to follow a deceleration pattern in adulthood were females $(\mathrm{OR}=3.6, p<.001)$ and those with an earlier age at first court appearance $(\mathrm{OR}=.68$, $p<.001)$.

Surviving Offending in Adulthood Table 4 presents the estimated survival probabilities for four distinct adult offending outcomes, that is, general offending (any criminal conviction), serious offending, violent offending, and sexual offending. The findings reported in Table 4 are based on the Kaplan-Meier product limit estimator [36]. Also, all survival analyses conducted in the study included inspection of both the KaplanMeier estimator and the Cox proportional hazard estimates [14], the two most commonly used estimators in criminal recidivism research (e.g., [27, 70]). There were minor non-significant differences between parameter estimates from the two methods examined. Therefore, the findings from both methods led to the same conclusions. With that in mind, only the Kaplan-Meier estimates were reported. Two levels of information are presented for each outcome: the cumulated survival probabilities for the observational period and the average survival time (years) without being convicted. Hence, the cumulated survival probabilities for general offending was 0.21 and the average time spent in community without being convicted once was, on average, 2.8 years. In other words, the critical period marking a change from a non-offending to an offending state, after turning 18 years old, was around 20 years old. The cumulated survival probabilities increased from serious (.35), violent (.44), and sex offending (.92), with the vast majority of young offenders not being convicted for a sex crime in early adulthood. For serious and violent offending, the switch from a nonoffending state to an offending state occurred at around 22 years old. The inspection of covariates indicates that females, as opposed to males, survived general offending $(\mathrm{OR}=.54, p<.001)$, serious offending $(\mathrm{OR}=.32, p<.001)$, violent offending $(\mathrm{OR}=.25, p<.000)$ longer in the community after turning 18 years old, but not sex offending. Survival estimates did not significantly vary across ethnic groups. Age at first court appearance was significantly associated with sex offending $(\mathrm{OR}=1.8$,

Table 4 Estimated survival probabilities for different forms of adult offending using Kaplan-Meier estimator

\begin{tabular}{lll}
\hline Adult offending & Cumulated survival probabilities & Average survival time \\
\hline General offending & $.21(.02)$ & $2.8(.12)$ \\
Serious offending & $.35(.03)$ & $4.9(.12)$ \\
Violent offending & $.44(.03)$ & $4.4(.13)$ \\
Sexual offending & $.92(.02)$ & $5.7(.06)$
\end{tabular}


$p<.001$ ), with youth who first appeared in court later in adolescence being less likely to have survived the follow-up period without being convicted of a sex crime.

\section{Comparison of Indicators of Desistance}

In this section, the four operationalizations of desistance are compared to assess the degree of convergence across measures. To do this, group membership in offending trajectories were cross-tabulated with the other three measures of desistance (nonoffending state, deceleration, and survival estimates) from crime. Findings are reported in Table 5. Offending trajectories are first compared to the maintenance of a nonoffending state throughout early adulthood. Four key findings were implicated from this comparison. First, individuals following a low rate trajectory and a bell-shaped trajectory were those showing evidence of a non-offending state in adulthood, suggesting that there could be two possible paths to termination from offending after turning 18 years old. Second, the findings also highlighted that the group-based modeling strategy did not identify a pure group of "desisters" or at least one consistent with the definition of a non-offending state in early adulthood. Third, the bell-shaped group, reminiscent of the adolescent-limited pattern, was composed of about $31 \%$ of individuals who maintained a non-offending state throughout adulthood, suggesting that the majority of these offenders were still involved in crime even after turning 18 years old, albeit at a very low rate. Fourth, about half of the low rate group maintained a nonoffending state throughout adulthood, suggesting that, while their offending as a group was very sporadic, it had yet to terminate for a substantial proportion of them. As expected, none of the two groups of chronic offenders (i.e., the high-rate chronic trajectory and the slow-rising chronic trajectory) maintained a non-offending state throughout adulthood.

When offending trajectories were cross-tabulated with deceleration patterns in adulthood, a somewhat different picture emerged. Indeed, the findings show that across the four offending trajectories, there is a sizeable proportion of offenders decelerating after turning 18 years old. About three-quarters of individuals following a bell-shaped trajectory are decelerating in adulthood, in line with the age-crime curve. About twothirds of the low rate and one-third of the high-rate chronics are decelerating in adulthood. In other words, deceleration is not limited to chronic offenders. In contrast to the high-rate chronics, only $16.3 \%$ of the slow-rising chronics are decelerating in early adulthood, suggesting that chronic offenders are not a homogeneous group following the same trajectory to desistance. Finally, it is noteworthy that across the four groups, only a limited number of individuals show an acceleration pattern after turning 18 years old, with only the slow-rising chronics having a substantial proportion of individuals whose offending behavior is still rising. But clearly, the overall trend is that, for most individuals included in this sample, offending is either stable or decelerating after turning 18 years old.

The four offending trajectories were then compared in terms of probabilities of desistance by looking at the cumulative survival time before a first offense (any, serious, violent, or sexual) in adulthood. The findings demonstrate some convergence between offending trajectories and survival patterns, at least to some extent. The two 


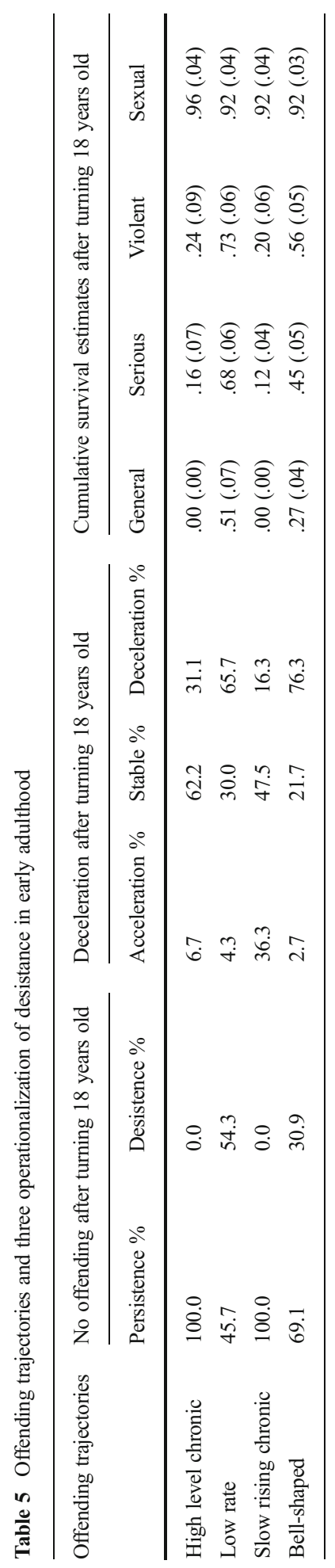


chronic trajectory groups, the slow-rising and the high-rate, showed the lowest probabilities of surviving the follow-up period in adulthood without committing any crime, a serious crime and a violent crime compared to the low rate and the bell-shape group (all Tarone-Ware estimates are showing $p$ values $<.01$ ). The similarities between the high-rate and the slow-rising chronics is concerning given that the offending rate of the two groups is going in opposite directions. Specifically, the high-rate chronics are following a downward trajectory in adulthood whereas the slow-rising chronics are following a trajectory of offending that has remained stable in adulthood. In other words, the survival estimate does not capture the dynamic aspect of their respective offending. Note that the four trajectory groups showed comparable survival estimates with respect to sex offending (Tarone-Ware estimate was not significant). Furthermore, while a substantial proportion of low rate and bell-shaped offenders maintained a nonoffending state after turning 18 years old, it is noteworthy that those who persisted, especially among the bell-shaped offenders, were involved in serious and/or violent crimes. In fact, the survival probabilities of the bell-shaped group was .45 for serious and .56 for violent crimes. In other words, the offending of the so-called adolescentlimited offenders has considerably slowed down after turning 18 years old; but for those still active, the offenses they were involved in were not trivial.

\section{Juvenile Subtypes and Desistance from Crime}

Next, subtypes of juvenile offenders were compared in terms of four different operationalizations of desistance from crime in adulthood. Four indicators were used to distinguish juvenile offenders, that is delinquency status or whether youth were chronic offenders, serious offenders, violent offenders, and sex offenders. Separate models were conducted to determine whether subtypes of juvenile offenders were different in terms of their pattern of desistance from crime in early adulthood. Logit regression models helped to determine whether juvenile offender subtypes had (a) maintained a non-offending state during adulthood (model 1) and (b) whether youth had shown a pattern of deceleration in adulthood (model 2). To conduct this second series of logit regression models, categories of acceleration of offending and stability of offending were collapsed into a single category to which deceleration was compared to. Juvenile subtypes were also compared in terms of their offending trajectories. More specifically, the outcome measure in a multinomial regression analyses (model 3) was created by collapsing chronic offenders (high rate and slow rising) into one group and comparing them to the trajectories suggesting a pattern of desistance in adulthood, that is the bell-shaped and the low-rate patterns. Finally, in the fourth model, juvenile offender subtypes were compared in terms of their survival rates using the KaplanMeier estimator. All findings are reported in Table 6.

Overall, when comparing juvenile offender subtypes, the findings highlighted some key differences across the four measures of desistance. Chronic juvenile offending was associated with the four outcome measures of desistance from crime in adulthood. In model 1, chronic offenders were less likely (13.3 \%) than recidivists and non-recidivists to maintain a non-offending state after turning 18 years old. Chronic offenders, however, were those showing the highest proportion of offenders $(64.7 \%)$ decelerating their offending from adolescence to adulthood compared to the other two groups (see model 2). Furthermore, half of chronic offenders were following a bell-shaped 


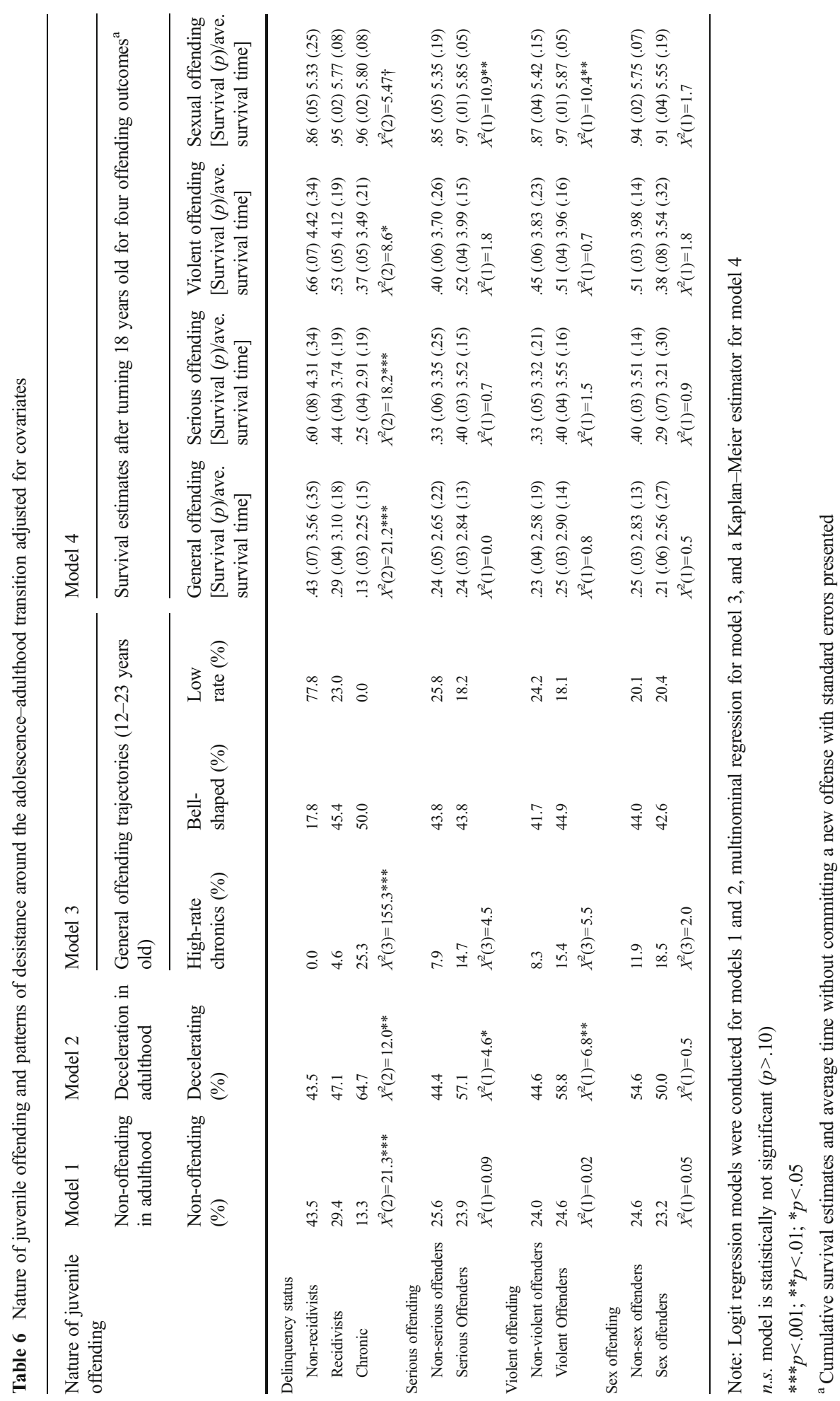


offending trajectory (model 3), which somewhat mirrors what is typically referred to as adolescent-limited offending. Chronic offenders were also those surviving general ( 2.4 years) and violent offending (4.5 years) the shortest in adulthood compared to juvenile recidivists and juvenile non-recidivists (model 4).

The findings also highlighted that serious, violent, and juvenile sex offender status were not very informative of desistance from crime in adulthood. The comparisons did not reveal significant statistical differences in terms of maintaining a non-offending state in adulthood nor were they associated with offending trajectories more likely to show a pattern of desistance around the adolescence-adulthood transition. Perhaps counter-intuitively, it is interesting to note that the findings did reveal that serious juvenile offenders $(57.1 \%)$ were more likely to show a deceleration pattern in adulthood than non-serious offenders. The same finding was observed for violent offending where deceleration from offending was more evident in violent juvenile offenders $(58.8 \%)$ than non-violent offenders. It is telling that in both cases, more than half of serious juvenile offenders and more than half of violent juvenile offenders showed a deceleration pattern in adulthood.

Finally, the survival analyses demonstrated that a particular subtype of juvenile offender was at-risk of adult sex offending in adulthood. In line with the previous observation, chronic offenders were the group most likely to be convicted of a crime in early adulthood (cumulative survival probabilities $[\mathrm{CSP}]=.13$ ) and were also more likely to be convicted of a serious crime $(\mathrm{CSP}=.25)$ and a violent crime $(\mathrm{CSP}=.37)$ compared to recidivists and non-recidivists. These three survival models were significant at $p<.05$. In other words, the status of chronic offending is pivotal in the identification of youth at-risk of the most serious and violent forms of adult offending. This finding is particularly telling in the context that, as the results show: (a) serious offending in adolescence was not predictive of a serious offense in early adulthood, (b) violent offending during adolescence was not predictive of adult violent offending, and (c) juvenile sex offending was not predictive of adult sex offending. In other words, the study did not highlight much evidence of homotypic continuity across the adolescenceadulthood transition. The study also showed the particularities of the continuity of offending and adult sex offending. Indeed, the study findings demonstrate that it is not the juvenile sex offender group who was at most risk of being convicted of a sex offense in adulthood, but of the group of youth who had a limited, non-serious, and non-violent juvenile offending record. In other words, among this pool of incarcerated juvenile offenders, it is the group with the least active and least serious delinquency profile who were at greater risk of being convicted for a sex crime, albeit that their risk of sex offending in adulthood was still relatively low.

\section{Discussion}

Given the assumption of continuity of offending among incarcerated young offenders involved in chronic, serious, violent, and/or sex offending, the patterns of desistance from crime around the adolescence-adulthood transition were examined in the current study. In line with this assumption, our findings echo those reported previously by Tracy and Kempf-Leonard's [80] which suggest that there is more continuity than discontinuity in offending. Indeed, only approximately $25 \%$ of incarcerated youth in 
this sample maintained a non-offending state in adulthood and the probabilities of general offending in adulthood were relatively high. These observations, however, provide an incomplete picture of the dynamics of offending across the adolescenceadulthood transition. When special categories or subgroups of incarcerated offenders were examined, the general level of offending significantly declined in adulthood. In other words, consistent with previous studies (e.g., Stouthamer [51, 53]), the findings indicated considerable discontinuity in that, for example, the serious, violent, or sexual adolescent offender did not necessarily become the serious, violent, or sexual adult offender, respectively. The only exception to this trend was the group of chronic adolescent offenders that were associated with continuity of offending in adulthood, irrespective of the conceptualization of desistance (see also [80]). This observation suggests that continuity of offending was more important for the quantitative than the qualitative aspect of offending across the two time periods. In all, the study showed the importance of using multiple conceptualizations of desistance to better capture the dynamics of offending in early adulthood.

Using this approach, the study challenged a major theme in the literature that most, if not all, incarcerated juvenile offenders are on a life-course persistent offending pattern. Instead, this study highlighted that much heterogeneity exists in the adult offending outcome patterns within this group of young offenders. Four conceptualizations and operationalization of desistance from crime were measured and tested in a sample of adolescents offenders in detention: (a) desistance as an event or the maintenance of a non-offending state after turning 18 years old; (b) desistance as a process or deceleration in offending after turning 18 years old; (c) offending trajectories; and (d) the probabilities of desistance. As a group, the offending of incarcerated young offenders slowed down in many ways in adulthood. About one-quarter of these young offenders maintained a non-offending state during the follow-up in adulthood, while about half of them decelerated. Furthermore, the study findings highlighted the relatively transient nature of serious types of offending. Obviously, not all incarcerated youth completely desisted from offending. Quite the contrary, the vast majority of the sample were convicted again in adulthood. The four conceptualizations of desistance, however, helped providing a more complete depiction of the patterns of continuity and discontinuity in offending around the adolescence-adulthood transition. These varied patterns need to be more fully integrated into the assessment of risk and needs of young offenders and individual case planning.

\section{Desistance: Toward a Unifying Concept}

There is an absence of a conceptual consensus concerning desistance as well as how it should be measured (e.g., Mulvey et al. 2001; [65, 77]). The current study examined four conceptualizations of desistance that are not necessarily contradictory. These conceptualizations somewhat overlap on certain aspect of desistance but also capture relatively distinctive aspects of an underlying process. Further, these four conceptualizations, together, appear to provide a more complete picture of desistance from crime. First, this study suggests that desistance is not a random process. Foremost, it is relatively bounded to the precocity and the level of prior involvement in crime and delinquency. Of importance, the study demonstrated the presence of four offending trajectories each characterized by a distinct pattern of desistance in terms of timing, 
deceleration, and probabilities of reoffending. Clearly, therefore, desistance is diverse and complex especially during the late adolescence to young adulthood transition period. Second, desistance involves a deceleration process prior to termination. It is likely activated by significant negative life events or negative consequences associated with offending, from physical injuries sustained during the commission of crimes to the impact of legal sanctions (e.g., [15]). For incarcerated young offenders, desistance most likely involves a series of relapses during the transition period. In effect, zigzag criminal careers best characterizes the most typical dynamic [43]. It appears also that deceleration is intrinsically related to the velocity of offending prior to the start of deceleration of offending. To illustrate, the faster a car is moving, the longer it will take to stop and immobilize the vehicle once the driver decides to engage the brake. In line with this example, our study showed that deceleration was the most important among the group of chronic juvenile offenders, even though chronic offenders remained the most criminally active group in early adulthood. In other words, all things being equal, the more important offending becomes, the longer the deceleration phase will last.

Third, desistance implies the probability of maintaining a non-offending state over time. Young offenders who maintained a non-offending state might, with a longer follow-up period, move back to an offending state. Even with protective factors such as within-individual changes or social-contextual factors promoting the deceleration of offending, negative life events (e.g., alcohol/drug use, financial difficulties, significant interpersonal conflicts, and negative mood) may favor the movement away from a nonoffending state back to an offending state (e.g., [84]). Given the heterogeneity in the probabilities of offending in adulthood and that these probabilities are not static, but dynamic and subject to several factors starting with the process of aging (e.g., [41]). In other words, with age, the probabilities of a relapse decrease. Residual probabilities of offending is expressed, among other things, by the substantial proportion of "adolescent-limited" offenders, labeled as bell-shaped offenders in the current study, who reoffended in adulthood. Again, this finding further supports the view of desistance as a process. Moreover, as our findings show, these probabilities are also gender distinctive; females are less likely than males to continue offending over long time periods. Fourth, termination of offending or the maintenance of a non-offending state over time may be difficult to achieve around the adolescence-adulthood transition for youth whose prior delinquency involvement is more frequent, where the deceleration has not started, and the probabilities of reoffending remain relatively high. Taken together, the proposed unified concept of desistance encompasses the combination of population heterogeneity and state-dependent processes.

Empirical evidence suggests that most of these individuals were not on a life-course pattern of offending but rather at different stages of desistance. Indeed, the study highlights the presence of four distinct offending trajectories, each being relatively distinct regarding onset, timing of the peak of offending, and the rate of offending across the study period. Of those four identified offending patterns, three manifested some evidence of desistance occurring around the adolescence-adulthood transition (i.e., high-rate chronics, low-rate offenders, and the bell-shaped offenders). For some, desistance appears to start in middle/late adolescence (bell-shaped and low rate), while for others (high-rate chronics), desistance occurs around the transition into adulthood. Also, for high-rate chronics, the transition to adulthood can involve the initiation of a deceleration process that, in itself, may not be sufficient to both decrease the 
probabilities of reoffending and create conditions necessary for the maintenance of a non-offending state. For other young offenders in this study, the start of desistance is evidenced by a decelerating pattern in the rate of offending. The process of deceleration, though, may be either relatively short and prompt (i.e., low rate), more gradual over a portion of adolescence (i.e., bell-shaped) or delayed and more progressive (i.e., high-rate chronics). For other young offenders included in the study, the adolescenceadulthood transition may have a limited impact on deceleration, and, consequently has no impact or a limited impact on decreasing the probabilities of reoffending (i.e., slowrising chronics). This group of juvenile offenders, not well documented in the criminological literature, may not benefit from the same turning points that other offenders benefit from. In all, at this early stage of research on desistance from criminal behavior, the study findings illustrate the importance of inspecting, comparing, and even integrating multiple conceptualization of desistance to better capture the dynamics of offending over time (see also, [38]). Future research should incorporate additional parameters of desistance to determine whether deceleration of the frequency of offending as observed for this sample was accompanied by a de-escalation in terms of seriousness of offending over time.

\section{Policy Implications}

Special categories of juvenile offenders, such as chronic, serious, violent, and sex offenders often are considered to be strongly associated with long-term persistent offending. In several countries, including Canada and the USA, this largely mediadriven perception of serious young offenders becoming serious and violent young adult offenders has been important in crime control strategies. Another related policy theme related to this perception is the increased utilization of the risk management-oriented model in juvenile justice systems [31]. This entails juvenile justice system personnel employing carefully validated instruments both for recidivism risk assessment and treatment programs and interventions at the individual case management level for each serious and violent offender (for a review, [44]). These risk/need assessment instruments are designed to assess the risk factors associated with reoffending and the needs or factors that can be modified through intervention and treatment that most likely decrease the risk of reoffending (e.g., [29]). Several risk/need instruments have been developed specifically for violent and sexual reoffending, which are based on two essential principles: (a) high-risk offenders should receive more intensive services and (b) program interventions should match the specific needs of the person assessed (e.g., $[7,52])$. These instruments, though, only consider one desistance dimension, i.e., probability of reoffending (frequently involving ordinal low, moderate, and high-risk categories). Based on this study's results, a more nuanced or more specified approach warrants consideration especially regarding the selection of treatment interventions. For example, these instruments do not take into consideration whether the youth's offending is more characteristic of a low-rate pattern, a high-rate chronic offending pattern, a bell-shaped, or a slow-rising pattern and, therefore, the most probable course of offending over time. It does not consider whether the youth's offending is stabilizing or in the process of decelerating. These risk assessment instruments and their design, in many respects, mirror those developed for adult offenders with similar limitations (e.g., [30]). 
Theoretically, the main concern is that these risk assessment tools are not sufficiently developmentally informed because they do not appropriately consider the inherently complex developmental changes and the dynamic nature of offending over time (e.g., [54]). Indeed, distinguishing young offenders in terms of their probabilities of reoffending (i.e., low risk, moderate risk, and high risk) speaks little of the dynamics of offending across adolescence, patterns of continuity, and discontinuity around the adolescence-adulthood transition. This fundamental limitation likely is very important in explaining why evaluative studies more frequently report inconsistent predictive accuracy in risk/need assessment tools for juvenile offenders (e.g., [59, 84]) compared to what is reported for adult offenders (e.g., [2]). Although the current study did not examine specific factors, the findings suggest that important needs and protective factors remain unidentified or misidentified if appropriate measures of desistance are not used. Given that criminal justice professionals working with youth will obviously be unaware of their patterns of offending in adulthood, examining the chronicity of offending at this adolescent stage will be important as those chronic offenders who do desist will still be involved in a longer slowing down process. At a minimum, it is suggested here that adjudicated youth assessment protocols should include measures of desistance designed specifically for this population. Without such a measure to guide and assist clinical assessment, it is suggested that clinicians and practitioners will continue to run into issues of overestimation of risk for some and underestimation of risk for others. Given the distinctive patterns of desistance between males and females, such assessment instruments should be gender-specific. Indeed, using instruments designed for male with female offenders may lead clinicians to overestimate the risk of recidivism and underestimate the likelihood of desistance.

\section{Limitations and Conclusions}

The study is not without limitations. First, the inclusion of both self-report and official data on offending would have provided a more complete picture of offending. While the complementary aspect of self-report and official is undeniable, it remains a significant challenge to collect both types of data in longitudinal studies of incarcerated young offenders, especially data on serious, violent, and sexual offending. It could be reasonably argued, as a result, that this research only captures serious offenses but inspection of the nature of offenses these individuals were charged and convicted, for were relatively minor, such as minor theft and offenses related to the administration of justice (for a detailed analysis of the crime mix for this sample, see [56]). Second, a longer follow-up period in adulthood is preferable to better assess long-term patterns of desistance, especially termination of offending. However, the study focused on the adolescence-adulthood transition and its impact on the longitudinal pattern of offending. Additionally, the study did not examine patterns of escalation and deescalation in seriousness, which may be a complementary dimension of the proposed conceptualization of desistance from crime. Among the offenders showing a relatively stable pattern of offending, therefore, it is possible that relatively less (or more) serious crime types over time might have been evident. This is an important consideration given that the study did not find substantial continuity for violent and sexual offending from adolescence to adulthood. Moreover, the study did not include a complete 
examination of all possible statistical modeling strategies of desistance and desistance patterns. For example, additional modeling strategies of offending trajectories include latent-growth curve modeling (e.g., [18]), while there are other hazard modeling strategies to study criminal recidivism, using for example, the Weibull, gamma, and the lognormal distribution (e.g., [1, 48]). Given the findings of the Bushway et al. [9] study as well as those reported in the current study, future empirical studies should examine and contrast these models of desistance. Finally, the study did not examine the role and impact of the criminal justice system (e.g., sanctions, interventions, treatment) on criminal careers in adulthood.

With that in mind, the current study affirms the importance of examining both the continuity and discontinuity in offending in chronic, serious, violent, and/or sexual offenders. While this group has been typically associated with the label of life-course persisters, these study findings reveal a more nuanced pattern of offending around the adolescence-adulthood transition. Most importantly, there is considerable heterogeneity in their offending and heterogeneity in desistance from offending. Four conceptualizations of desistance were considered with their respective strengths and limitations. The results highlight the somewhat complementary nature of these measures of desistance and stress the multidimensional structure of desistance. In addition, at least for more serious young offenders such as those in this study, desistance appears more validly conceptualized as a process that is relatively short and abrupt for some, delayed and progressive for others. A subgroup of incarcerated offenders whose offending remains relatively unchanged following the adulthood transition is evident as well, which is counterintuitive to the typical age-crime curve. These slow-rising chronics should be the subject of future studies to better understand their distinctive course of offending. Furthermore, the aim of the study was not to examine the covariates of desistance, but rather to explore different conceptual and operational definitions of desistance. Given the study findings, future studies should not only examine the covariates of desistance, but also whether the same factors are associated with different conceptualizations and operationalizations of desistance.

\section{Appendix A}

Table 7 Bayesian information criteria values per model

\begin{tabular}{ll}
\hline Number of groups & Bayesian information criteria \\
\hline 1 & $-7,832.60$ \\
2 & $-7,348.53$ \\
3 & $-7,244.01$ \\
4 & $-7,127.21$ \\
5 & $-7,170.14$
\end{tabular}

Note: Bold face type indicates selected model 


\section{References}

1. Allison, P. D. (2010). Survival analysis using SAS: a practical guide. Cary: SAS publishing.

2. Andrews, D. A., Bonta, J., \& Wormith, J. S. (2006). The recent past and near future of risk and/or need assessment. Crime and Delinquency, 52, 7-27.

3. Ayres, C. D., Williams, J. H., Hawkins, J. D., Peterson, P. L., Catalano, R. F., \& Abbott, R. D. (1999). Assessing correlates of onset, escalation, deescalation, and desistance of delinquent behavior. Journal of Quantitative Criminology, 15(3), 277-306.

4. Bala, N., Carrington, P., \& Roberts, J. (2009). Evaluating the YCJA after five years: a qualified success. Canadian Journal of Criminology and Criminal Justice, 51, 131-167.

5. Blokland, A. A., \& Nieuwbeerta, P. (2005). The effects of life circumstances on longitudinal trajectories of offending. Criminology, 43, 1203-1240.

6. Blokland, A. A. J., Nagin, D., \& Nieuwbeerta, P. (2005). Life span offending trajectories of a Dutch conviction cohort. Criminology, 43, 919-954.

7. Borum, R., Bartel, P., \& Forth, A. (2005). Structured Assessment of Violence Risk in Youth (SAVRY). In T. Grisso, G. Vincent, \& D. Seagrave (Eds.), Mental health screening and assessment in juvenile justice (pp. 311-323). New York: Guilford.

8. Bushway, S. D., Piquero, A. R., Broidy, L. M., Cauffman, E., \& Mazerolle, P. (2001). An empirical framework for studying desistance as a process. Criminology, 39, 491-516.

9. Bushway, S. D., Thornberry, T. P., \& Krohn, M. D. (2003). Desistance as a developmental process: a comparison of static and dynamic approaches. Journal of Quantitative Criminology, 19, 129-153.

10. Cernkovich, S. A., \& Giordano, P. C. (2001). Stability and change in antisocial behavior: the transition from adolescence to early adulthood. Criminology, 39, 371-410.

11. Cernkovich, S. A., Giordano, P. C., \& Pugh, M. D. (1985). Chronic offenders: the missing cases in selfreport delinquency research. Journal of Criminal Law \& Criminology, 76, 705-732.

12. Corrado, R. R. (2002). An introduction to the risk/needs case management instrument for children and youth at risk for violence: the Cracow Instrument. In R. R. Corrado, R. Roesch, S. D. Hart, \& J. K. Gierowski (Eds.), Multi-problem violent youth: a foundation for comparative research on needs, interventions, and outcomes (pp. 295-301). Oxford: IOS Press.

13. Corrado, R. R., Cohen, I. M., Glackman, W., \& Odgers, C. (2003). Serious and violent young offenders' decisions to recidivate: an assessment of five sentencing models. Crime \& Delinquency, 49, 179-200.

14. Cox, D. R. (1972). Regression models and life tables. Journal of the Royal Statistical Society, B34, 187220.

15. Cusson, M., \& Pinsonneault, P. (1986). The decision to give up crime. Cornish, D.B and R.V. Clarke (eds.) The reasoning criminal: rational choice perspectives on offending (p.72-82). NY: Springer.

16. Descormiers, K. (2013). From getting in to getting out: the role of pre-gang context and group processes in analyzing turning points in gang trajectories. Ph.D. Dissertation. Simon Fraser University, Burnaby, British Columbia.

17. Dubow, E. F., Huesmann, L. R., Boxer, P., \& Smith, C. (2014). Childhood predictors and age 48 outcomes of self-reports and official records of offending. Criminal Behaviour and Mental Health, 24, 291-304.

18. Duncan, T. E., Duncan, S. C., \& Strycker, L. A. (2013). An introduction to latent variable growth curve modeling: concepts, issues, and application. Routledge.

19. Farrall, S., \& Calverley, A. (2006). Understanding desistance from crime. Maidenhead: Open University Press.

20. Farrington, D. P. (1986). Age and crime. In M. Tonry \& N. Morris (Eds.), Crime and justice: an annual review of research. Vol. 7 (pp. 189-250). Chicago: University of Chicago Press.

21. Farrington, D. P. (1997). Early prediction of violent and non-violent youthful offending. European Journal on Criminal Policy and Research, 5, 51-66.

22. Farrington, D. P., Osborn, S. G., \& West, D. J. (1978). The persistence of labelling effects. The British Journal of Criminology, 18, 277-284.

23. Farrington, D. P., Ttofi, M. M., Crago, R. V., \& Coid, J. W. (2014). Prevalence, frequency, onset, desistance and criminal career duration in self-reports compared with official records. Criminal Behaviour and Mental Health, 24(4), 241-253.

24. Fontaine, N. M., Lacourse, E., Vitaro, F., \& Tremblay, R. E. (2014). Links between trajectories of selfreported violent and nonviolent offending and official offending during adolescence and adulthood. Criminal Behaviour and Mental Health, 24, 277-290.

25. Gendreau, P., Little, T., \& Goggin, C. (1996). A meta-analysis of the predictors of adult offender recidivism: what works! Criminology, 34, 575-607. 
26. Gilman, A. B., Hill, K. G., Kim, B. K., Nevell, A., Hawkins, J. D., \& Farrington, D. P. (2014). Understanding the relationship between self-reported offending and official criminal charges across early adulthood. Criminal Behaviour and Mental Health, 24, 229-240.

27. Hanson, R. K., \& Thornton, D. (2000). Improving risk assessments for sex offenders: a comparison of three actuarial scales. Law and Human Behavior, 24, 119.

28. Hindelang, M. J., Hirschi, T., \& Weis, J. G. (1981). Measuring delinquency. Beverly Hills: Sage Publications.

29. Hoge, R. D. (2005). Youth level of service/case management inventory. In T. Grisso, G. Vincent, \& D. Seagrave (Eds.), Mental health screening and assessment in juvenile justice (pp. 283-294). New York: Guilford.

30. Hoge, R., Vincent, G., \& Guy, L. S. (2012). The prediction and risk and need assessment of early adult criminal activity. In R. Loeber \& D. P. Farrington (Eds.), Transitions from juvenile delinquency to adult crime: criminal careers, justice policy, and prevention (pp. 150-183). New York: Oxford University Press.

31. Howell, J. C., Feld, B. C., \& Mears, D. P. (2012). Young offenders and an effective justice system response: What happens, what should happen, and what we need to know. In R. Loeber \& D. P. Farrington (Eds.), Transitions from juvenile delinquency to adult crime: criminal careers, justice policy, and prevention. New York: Oxford University Press.

32. Jolliffe, D., Farrington, D. P., Hawkins, J. D., Catalano, R. F., Hill, K. G., \& Kosterman, R. (2003). Predictive, concurrent, prospective and retrospective validity of self-reported delinquency. Criminal Behaviour and Mental Health, 13, 179-197.

33. Jones, B. L., \& Nagin, D. S. (2007). Advances in group-based trajectory modeling and an SAS procedure for estimating them. Sociological Methods \& Research, 35, 542-571.

34. Jones, B. L., Nagin, D. S., \& Roeder, K. (2001). A SAS procedure based on mixture models for estimating developmental trajectories. Sociological Methods \& Research, 29, 374-393.

35. Junger-Tas, J., \& Marshall, I. H. (1999). The self-report methodology in crime research. Crime and Justice, 25, 291-367.

36. Kaplan, E. L., \& Meier, P. (1958). Nonparametric estimation from incomplete observations. Journal of the American Statistical Association, 53, 457-481.

37. Kazemian, L. (2007). Desistance from crime: theoretical, empirical, methodological, and policy considerations. Journal of Contemporary Criminal Justice, 23, 5-27.

38. Kazemian, L. (2014). Desistance from crime and antisocial behavior. In J. Morizot \& L. Kazemian (Eds.), The development of criminal and antisocial behavior: theory, research and practical applications (pp. 295-312). New York: Springer.

39. Kazemian, L., \& Farrington, D. P. (2012). Recherches sur les sorties de délinquance: Quelques limites et questions non résolues. In M. Mohammed (Ed.), Les sorties de délinquance: théories, méthodes, enquêtes. Paris: La Découverte.

40. Kazemian, L., \& Maruna, S. (2009). Desistance from crime. In M. D. Krohn, A. J. Lizotte, \& P. G. Hall (Eds.), Handbook on crime and deviance (pp. 277-296). New York: Springer.

41. Kurlychek, M. C., Brame, R., \& Bushway, S. D. (2007). Enduring risk? Old criminal records and predictions of future criminal involvement. Crime \& Delinquency, 53, 64-83.

42. Laub, J. H., \& Sampson, R. J. (2001). Understanding desistance from crime. Crime and Justice: An Annual Review of Research, 28, 1-69.

43. Laub, J. H., \& Sampson, R. J. (2003). Shared beginnings, divergent dives: delinquent boys to age 70. Massachusetts: Harvard University Press.

44. Le Blanc, M. (2002). Review of clinical assessment strategies and instruments for adolescent offenders. In R. R. Corrado, R. Roesch, S. D. Hart, \& J. K. Gierowski (Eds.), Multi-problem youth: a foundation for comparative research on needs, interventions and outcomes (pp. 171-190). Oxford: IOS Press.

45. Le Blanc, M., \& Fréchette, M. (1989). Male criminal activity from childhood through youth: multilevel and developmental perspective. New York: Springer-Verlag.

46. Le Blanc, M., \& Loeber, R. (1998). Developmental criminology updated. Crime and justice, 115-198.

47. Le Blanc, M., \& Kaspy, N. (1998). Trajectories of delinquency and problem behavior: comparison of social and personal control characteristics of adjudicated boys on synchronous and nonsynchronous paths. Journal of Quantitative Criminology, 14, 181-214.

48. Liu, X. (2012). Survival analysis: models and applications. Chichester: Wiley.

49. Loeber, R., \& Farrington, D. P. (1998). Serious and violent juvenile offenders: risk factors and successful interventions. Thousand Oaks: Sage.

50. Loeber, R., \& Le Blanc, M. (1990). Toward a developmental criminology. In M. Tonry \& N. Morris (Eds.), Crime and justice (pp. 375-473). Chicago: University of Chicago Press. 
51. Loeber, R., Farrington, D. P., Stouthamer-Loeber, M., \& White, H. R. (2008). Violence and serious theft: development and prediction from childhood to adulthood (pp. 3-24). New York: Routledge.

52. Lösel, F. (1995). The efficacy of correctional treatment: A review and synthesis of meta- evaluations. In J. McGuire (Ed.), What works: reducing reoffending, guidelines from research and practice (pp. 79-111). Chichester: John Wiley.

53. Lussier, P., \& Blokland, A. (2014). The adolescence-adulthood transition and Robins's continuity paradox: criminal career patterns of juvenile and adult sex offenders in a prospective longitudinal birth cohort study. Journal of Criminal Justice, 42, 153-163.

54. Lussier, P., \& Davies, G. (2011). A person-oriented perspective on sexual offenders, offending trajectories, and risk of recidivism: a new challenge for policymakers, risk assessors, and actuarial prediction? Psychology, Public Policy, and Law, 17, 530.

55. Lussier, P., van den Berg, C., Bijleveld, C., \& Hendriks, J. (2012). A Developmental taxonomy of juvenile sex offenders for theory, research, and prevention: the adolescent-limited and the high-rate slow desister. Criminal Justice and Behavior, 39, 1559-1581.

56. Lussier, P., Corrado, R., \& McCuish, E. (2015). A criminal career study of the continuity and discontinuity of sex offending during the adolescence-adulthood transition: a prospective longitudinal study of incarcerated youth. Justice Quarterly.

57. Maruna, S. (2001). Making good: how ex-convicts reform and rebuild their lives. Washington: American Psychological Association.

58. McCuish, E. C., Lussier, P., \& Corrado, R. R. (2015). Criminal careers of juvenile sex and non-sex offenders: evidence from a prospective longitudinal study. Youth Violence and Juvenile Justice. doi:10. $1177 / 1541204014567541$.

59. Meyers, J. R., \& Schmidt, F. (2008). Predictive validity of the Structured Assessment for Violence Risk in Youth (SAVRY) with juvenile offenders. Criminal Justice and Behavior, 35(3), 344-355.

60. Moffitt, T. E. (1993). "Life-course-persistent" and "adolescent-limited" antisocial behaviour: a developmental taxonomy. Psychological Review, 100, 674-701.

61. Mulvey, E. P., Steinberg, L., Fagan, J., Cauffman, E., Piquero, A. R., Chassin, L., \& Losoya, S. H. (2004). Theory and research on desistance from antisocial activity among serious adolescent offenders. Youth Violence and Juvenile Justice, 2, 213-236.

62. Nagin, D. S. (2005). Group-based modeling of development. Cambridge: Harvard University Press.

63. Ouimet, M., \& Blanc, M. L. (1996). The role of life experiences in the continuation of the adult criminal career. Criminal Behaviour and Mental Health, 6, 73-97.

64. Patterson, G. R., \& Yoerger, K. (1993). Developmental models for delinquent behavior. In S. Hodgins (Ed.), Mental disorder and crime (pp. 140-172). Thousand Oaks: Sage.

65. Piquero, A. R. (2009). Methodological issues in the study of persistence in offending. In J. Savage (Ed.), The development of persistent criminality. Oxford: Oxford University Press.

66. Piquero, A. R., Blumstein, A., Brame, R., Haapanen, R., Mulvey, E. P., \& Nagin, D. S. (2001). Assessing the impact of exposure time and incapacitation on longitudinal trajectories of criminal offending. Journal of Adolescent Research, 16, 54-74.

67. Piquero, A. R., Farrington, D. P., \& Blumstein, A. (2003). The criminal career paradigm. Crime and Justice, 30, 359-506.

68. Piquero, A. R., Farrington, D. P., \& Blumstein, A. (2007). Key issues in criminal career research: new analyses of the Cambridge Study in Delinquent Development. Cambridge: Cambridge University Press.

69. Pogarsky, G., \& Piquero, A. R. (2003). Can punishment encourage offending? Investigating the "resetting" effect. Journal of Research in Crime and Delinquency, 40, 95-120.

70. Rice, M. E., \& Harris, G. T. (1997). Cross-validation and extension of the Violence Risk Appraisal Guide for child molesters and rapists. Law and Human Behavior, 21, 231-241.

71. Rosenfeld, R., White, H., \& Esbensen, F. (2012). Special categories of serious and violent offenders: Drug dealers, gang members, homicide offenders, and sex offenders. In R. Loeber \& D. Farrington (Eds.), From juvenile delinquency to adult crime: criminal careers, justice policy, and prevention (pp. 118-149). New York: Oxford University Press.

72. Sampson, R. J., \& Laub, J. H. (2003). Life-course desisters? Trajectories of crime among delinquent boys followed to age 70. Criminology, 41, 555-592.

73. Sampson, R. J., \& Laub, J. H. (2005). A life-course view of the development of crime. The Annals of the American Academy of Political and Social Science, 602, 12-45.

74. Shover, N., \& Thompson, N. (1992). Age, differential expectations, and crime desistance. Criminology, 30, 89-104.

75. Skardhamar, T. (2010). Distinguishing facts and artifacts in group-based modeling. Criminology, 48, 295320. 
76. Stouthamer-Loeber, M., Loeber, R., Stallings, R., \& Lacourse, E. (2008). Desistance from and persistence in offending. In Violence and serious theft: development and prediction from childhood to adulthood (pp. 269-308). New York: Routledge.

77. Teplin, L.A., Abram, K. M., Washburn, J. J., Welty, L. J., Hershfield, J. A., \& Dulcan, M. K. (2013). Northwestern Juvenile Project: Overview. US Department of Justice, Office of Justice Programs, Office of Juvenile Justice and Delinquency Prevention.

78. Tolan, P. H., \& Gorman-Smith, D. (1998). Development of serious and violent offending careers. In R. Loeber \& D. Farrington (Eds.), Serious and violent juvenile offenders: risk factors and successful interventions (pp. 68-85). Beverly Hills: Sage Publications.

79. Tracy, P. E., \& Kempf-Leonard, K. (1996). Continuity and discontinuity in criminal careers. Springer.

80. Tzoumakis, S., Lussier, P., Le Blanc, M., \& Davies, G. (2013). Onset, offending trajectories, and crime specialization in violence. Youth Violence and Juvenile Justice, 11, 143-164.

81. Uggen, C. (2000). Work as a turning point in the life course of criminals: a duration model of age, employment, and recidivism. American Sociological Review, 65, 529-546.

82. Uggen, C., \& Massoglia, M. (2003). Desistance from crime and deviance as a turning point in the life course. In J. T. Mortimer \& M. J. Shanahan (Eds.), Handbook of the life course (pp. 311-329). New York: Kluwer.

83. Viljoen, J. L., Scalora, M., Cuadra, L., Bader, S., Chavez, V., Ullman, D., \& Lawrence, L. (2008). Assessing risk for violence in adolescents who have sexually offended: a comparison of the J-SOAP-II, JSORRAT-II, and SAVRY. Criminal Justice and Behavior, 35, 5-23.

84. Zamble, E., \& Quinsey, V. L. (1997). The process of recidivism. Cambridge: Cambridge University Press. 